\title{
Unsafe Use of Pesticide and Its Impact on Health of Farmers: A Case Study in Burichong Upazila, Bangladesh
}

\author{
Sheikh Jewel Miah ${ }^{1}$, Abdul Hoque ${ }^{2}$, Dr. Alak Paul ${ }^{3}$ and Dr. Arifur Rahman ${ }^{4}$ \\ ${ }^{1}$ Research Student, Dept. of Geography and Environmental Studies, University of Chittaogng, \\ ${ }^{2,3}$ Associate Professor, Dept. of Geography and Environmental Studies, University of Chittaogng, \\ ${ }^{4}$ Senior Scientific Officer, Bangladesh Agricultural Research Institute, Gazipur.
}

\begin{abstract}
Farmers of Bangladesh frequently use different types of pesticides in vegetable fields following the advice of untrained traders or salespersons. Three-fourths of farmers adopt safety measures partially but cannot avoid skin, eye, gastro-intestinal, urine and sexual and other diseases. Most farmers spray two days in a week but sometimes apply pesticides every day and harvest vegetable soon after; more than three-fourths don't know about the waiting period before collection. Consequently, pesticide residues (Diazinon and Quinalphos) are detected in $67 \%$ of marketed vegetables (long yard bean) which are above Acceptable Daily Intake (ADI). Respondents strongly believe that vegetables grown with the use of pesticide causes various chronic and acute diseases to consumers.
\end{abstract}

Key words: Bangladesh, Health impact, Pesticide, Residue analysis.

\section{Background and statement of the problem}

In Bangladesh, as in most developing countries, agriculture plays a key role in the overall economic performance of the country, not only in terms of its contribution to gross domestic product (GDP, 20.01\%), but also as a major source of foreign exchange earnings, and in providing employment (47.3\%) to a large segment of the population, particularly the poor [1]. Owing to the massive damage caused by pests to agricultural fields and crops, production often declines below the level of subsistence for farmers, which can eventually have adverse effects on the national economy. In the process of checking and killing pests over the years, pesticide application in Bangladesh has increased manifold from 758 metric tons in 1960 and 3028 metric tons in 1980 to over 19000 metric tons in 2000 [2] and in 2008, the amount of pesticide applied in fields across the country rose to 48690 metric tons [3]. Insecticides, being the dominant item, account for $76 \%$ of the pesticides applied in YEAR.

Farmers of Bangladesh mostly apply insecticides and a little amount of herbicides, fungicides, acaricides and rodenticides [4] in the vegetable field in the form of granules, liquid and powder. It has been reported that 20 insecticides, 18 fungicides and 2 rodenticides, are being used in Bangladesh [5]. The major pesticides used by the farmers are Cypermethrin, Dichlorvos, Malathion, Carbofuran, Mancozeb and Diazinon depending upon the invading pests in Bangladesh [6]. Besides, many pesticides used in Bangladesh are in the banned or restricted list under international agreements $[7,8,9,10]$.

Most farmers particularly in the developing countries like Bangladesh apply pesticide without knowing its actual requirements and/or effectiveness, and thus there are very high frequencies of pesticides application, for example, 150 sprays in a crop season in brinjal in Bangladesh [11]. More than 90\% farmers of Bangladesh use pesticide unnecessarily, indiscriminately and excessively due to their ignorance and unconsciousness about the use [12].

Farmers and workers of Bangladesh spraying pesticides in crop fields are highly vulnerable to various diseases as the job is most often done without taking any safety measures; they absorb the toxic item unaware in different ways, including inhalation. Most farmers of Bangladesh spray pesticides without wearing masks, gloves and other proper clothes [4]. Even, many farmers often blow air from the mouth through the spraying pipe to make it clear [13]. Over $87 \%$ farmers report to openly admit of using little or no protective measures while applying pesticides and $92 \%$ of them do not take any protective measures during use, storage, transport etc. [14]. Pesticides can enter into human body during and after application through its different parts. The rate of dermal absorption of pesticide residues varies with the parts of body such as scalp (3.7\%), forehead (4.2\%), ear canal $(5.4 \%)$, abdomen $(2.1 \%)$, forearm $(1.0 \%)$, palm $(1.3 \%)$, genital area $(11.8 \%)$ and ball of foot $(1.6 \%)[15]$. Organophosphate pesticides have spread in use, because they are less damaging to the environment and they are less persistent than organochlorine pesticides [16]. Of course, these are associated with acute health problems for workers that handle the chemicals, such as abdominal pain, dizziness, headaches, nausea, vomiting, as well as skin and eye problems [17].

There have been many studies on farmers intended to establish cancer-pesticides linkages and indicate that maternal employment in agriculture has a link with leukemia and populations living around the active 
agricultural regions are highly prone to cancer. Beginning in the late 1970s, there have been reports linking pesticides to leukemia in children [18] and exposure to non-Hodgkin lymphoma and leukemia [19]. Thyroid and bone cancers are prevalent in agricultural regions where fungicides are extensively used [20]. Moreover, organophosphate pesticides used in the vegetable gradually gets deposit into the human body and has a link with cancer [21,22].

Nowadays, urinary and sexual diseases have staggered throughout the world, to mention developing countries in particular. There is growing evidence of sterility in humans and various other animals, particularly in males due to exposures to various chemicals and pesticides in the environment. Sperm counts in Europe have declined by about $50 \%$ and continue to decrease by an additional $2 \%$ per year [23]. A study found that pesticide users of Bangladesh have suffered low level of testosterone with higher percentage of female children than male [6].

Consequences, pesticide exposure can cause a variety of human health problems, both chronic and acute in both farmers and consumers. Chronic effects are typically the result of low levels of exposure over a long period of time even if there are no acute or immediate effects. Major health impacts from chronic exposure include cancers, reproductive and endocrine disruption, neurological damage, and immune system dysfunction $[24,25,26]$. The World Health Organization (WHO) and the United Nations Environment Program estimate nearly 4.0 million people suffer from severe pesticide poisoning and its rate is $2-3$ per minute, with approximately 20,000 workers dying from exposure every year, the majority in developing countries $[27,28,29$, $30,31]$.

In addition, consumers are subjected to or affected by various types of food-borne diseases associated with pesticide contamination. It is well documented that a major portion of the pesticides is intercepted by the plant leaves during application. Vegetables such as tomatoes, country beans, cabbage, cauliflower and cucumber may receive higher doses of pesticides [6]. As a result, pesticide residues remain in the vegetable though not documented how much active material could be immanent in vegetables even after they are washed and cooked $[2,32]$.

Farmers of Bangladesh use pesticides in their fields to protect plants, buds and crops from harmful pests, particularly in vegetables such as red amaranth, spinach, cabbage, lady's finger, potato, tomato, eggplant, cauliflower and cucumber which are affected more than rice or other crops. According to Pesticides Association of Bangladesh (2002-2003), pesticide use for growing vegetables was six times higher than for the rice (1.12 $\mathrm{kg} / \mathrm{ha}$ for vegetables while it was only $0.20 \mathrm{~kg} / \mathrm{ha}$ in rice). Furthermore, farmers spray their vegetables $17-150$ times per crop cycle [6]. According to DAE, about 95 percent farmers do not wait for pre-harvesting interval (PHI) after application of pesticides [12]. Consequently, residues of pesticides are found in an alarming proportion on vegetable crops [33]. The amounts of detected residue of Diazinon were 0.54, 0.27, $0.14 \mathrm{ppm}$ and of Cypermethrin were 0.77, 0.54 and $0.27 \mathrm{ppm}$ respectively after 0,1 and 2 days of spraying at field concentration [2]. Another study shows that pesticides (cypermethrin, diazinon, quinalphos, fenotrothion and malathion) residue is found in number of vegetables such as brinjal, hyacinth bean, cauliflower and yard long bean samples collected from farmers' fields and markets of different regions e.g. yard long bean samples of Comilla contained residue of cypermethrin $(0.432 \mathrm{ppm})$, diazinon $(0.039 \mathrm{ppm})$ and malathion $(0.651 \mathrm{ppm})$ which was above Maximum Residue Limits (MRL) [34]. Moreover, most chronic diseases e.g., cancer, heart attack etc. are the result of long term consumption of pesticide contaminated vegetables. A consumer opinion survey indicates that, most of the U.S. citizens believe that pesticide residues in food are a serious cancer hazard [35]. It is reported that four children died and 13 others survived after becoming sick at Dhamrai Upazila, Dhaka due to overuse of pesticide [36]. Pesticide application in vegetable fields not only affects the farmers' health but also threat to the global human health.

I have reviewed wide literature found in different universities and related research organization, online libraries as well as contact with specialized persons about pesticides application and its impact on human health. In Bangladesh, no systematic study has so far been carried out to determine the pesticide residue level in vegetables to delve into the effects of pesticides on public health- for both farmers and consumers of contaminated vegetables. Though a few have been conducted in Bangladesh either based on analyzing residues or survey questionnaires none of the previous studies applied both the methods together. This current study has been carried out to establish a link between perception and laboratory analysis through questionnaire survey and residue analysis.

\section{Study objectives}

The study had three specific objectives: Firstly, to assess the level of pesticide use and precautionary measures usually adopted by the farmers during and after application in the study area; secondly, to determine the residues of pesticides persisting in marketed vegetables; and finally, to identify the consequences on human health due to the use of pesticides in vegetables fields. 


\section{Methods and design and of the study}

To assess the effects of pesticides' toxicity on the health of farmers and vegetable consumers in Burichong Upazila, Bangladesh, a primary field investigation was conducted from May, 2012 to August, 2012(Fig. 1). Because of, all vegetables mentioned are grown largely in the Burichong Upazila of Comilla district and supplied to different parts of the country, particularly to the two major cities, Dhaka and Chittagong, and even exported to the European countries. Data were collected from a total of 120 respondents of Bharella, Mokam and Rajapur unions of Burichong Upazila through survey questionnaires containing both structured and non-structured questions about duration of cultivation, types of pesticides use, pre-cautionary measures practice, waiting period of vegetable collection, experience of suffering from diseases during and after application of pesticide as well as consumption of vegetables, diseases that have been suffering etc. These unions were selected on the basis of having the highest, medium and lowest levels of vegetable production area and use of pesticides. Following a stratified simple random sampling technique, respondents were selected from local inhabitants cultivating vegetables and using pesticides for many years ( $\sim 30$ years). In addition, face-to-face key informant interviews were conducted by the researcher among 10 consultants and specialist doctors of skin, eye, medicine, urology, cardiology, neurology and cancer to understand potential effects of the pesticide on farmers and vegetable consumers' health within the region.

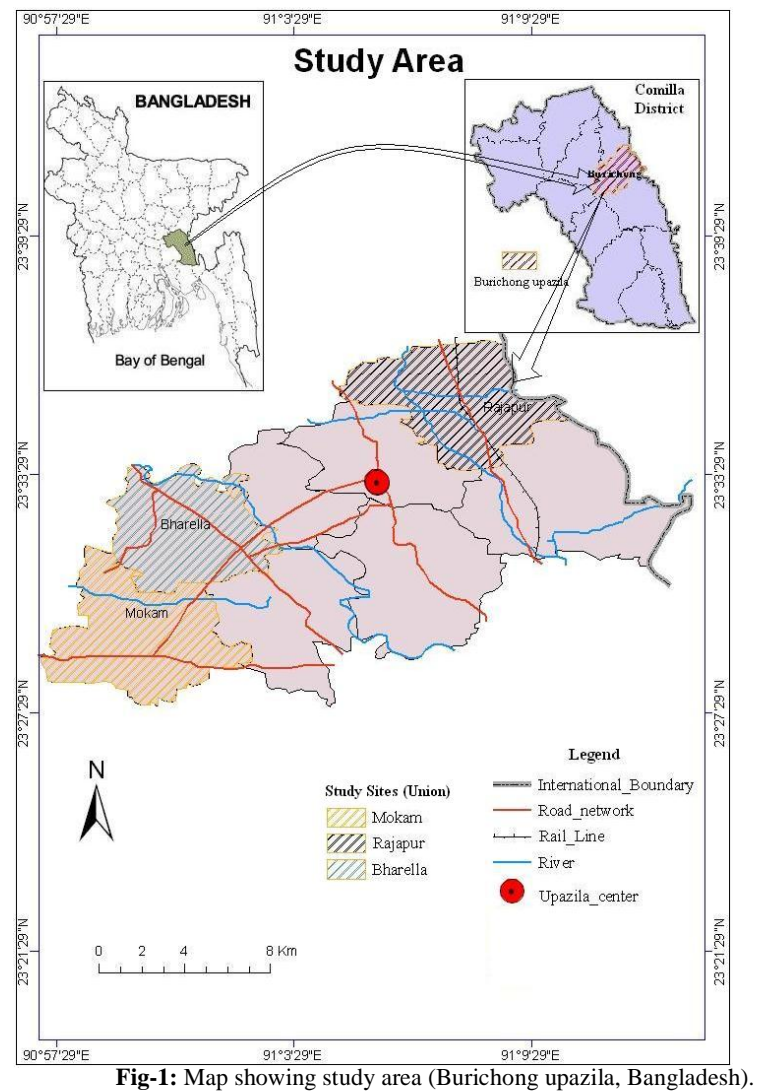

For analyzing pesticide residues in vegetables, six samples of cucumber and yard long beans were collect from three large and popular markets in the study area (Nimsar, Bharella and Sankuchail of Mokam, Bharella and Rajapur unions, respectively). All of the samples were collected during the period of July to August 2012 from the regions having high level pesticides use. Pesticide residues in the vegetable samples were analyzed in the Pesticide Research and Environmental Toxicology (PRET) lab at Bangladesh Agricultural Research Institute (BARI). The residues of organochlorine and organo phosphorous compounds in experimental samples were determined by Gas-chromatography (GC) and data analyzed using Excel and SPSS and software. However, all respondents surveyed are male who has been cultivating and using pesticides for long time $(\sim 30$ years). Farmers are learned from their ancestor about farming and did not get any formal training from government and non-government organizations. They are either primary educated or illiterate and have no enough knowledge about pesticide application and its possible impacts on human health. Moreover, they do not keep any written record of their farming activities. This study was approved by the research committee of the department of Geography and Environmental Studies, University of Chittagong, Bangladesh. 


\subsection{Types, level and interval of pesticide application}

\section{Results and discussions}

Types: The present study involving pesticide users reveals that all farmers use insecticides with the percentage of 80-90 compared to others pesticides. They use a variety of pesticides which are found under different trade names belonging to different chemical groups with different formulations e.g., emulsifiable concentrate (EC)- Cypermethrin (WHO class II), Quinalphos (WHO class III)Nitro, Karate, Sumithion, Ostad, Ripcord, Fyfanon, Marshal, Darsban, Sumesidin; soluable powder (SP)- Suntuf; granular (G)- Basudin, Diazinon (WHO class II), Cartuf, and Actara (WG). Commonly used pesticides are of the organophosphate chemical group though some of the farmers have also used carbamate and synthetic pyrethroid. The order of dominance use in the study area found in pesticides group are insecticides > fungicides $>$ herbicides while such order by class is organophosphates > synthetic pyrethroids> carbamates (Table-1).

Table -1: Trade name and chemical group of pesticides used in the study area.

\begin{tabular}{|l|l|c|}
\hline Trade name of used pesticide & Chemical group & \% of total respondent \\
\hline Basudin (gr) & Organophosphate & 64.2 \\
\hline Fyfanon (lq) & Organophosphate & 34.2 \\
\hline Darsban (lq) & Organophosphate & 82.5 \\
\hline Nitro (lq) & Organophosphate & 20.8 \\
\hline Karate (lq) & Organophosphate & 34.2 \\
\hline Sumesidin (lq) & Synthetic pyrethroid & 37.5 \\
\hline Cypermethrin (lq) & Synthetic pyrethroid & 29.2 \\
\hline Marshal (lq) & Carbamate & 57.5 \\
\hline Endofil (powder) & Mencozeb & 30.8 \\
\hline Bavistin (powder) & Carbendazin & 13.3 \\
\hline
\end{tabular}

( $\mathrm{gr}=$ granular, lq= liquid; multiple answers considered)

Level: This study found that $23 \%$ of applicators follow instructions written on bottles or packets while some $39 \%$ apply those according to the prescriptions from pesticide traders depending on the criteria of the fields described by the farmers. Generally, pesticide sellers are not properly trained up, they learn about pesticide from the representative of the company orally. Moreover, farmers complained that block supervisors or agricultural officials are rarely seen and do not get proper suggestions in time from them. Though, some $3 \%$ farmers use lower dosages due to shortage of cash, 34\% use higher dosages than the recommended level causes of inadequate knowledge of appropriate dosage and ignorance about pesticide toxicity (Table-2).

Interval: Pesticide application in the study area as well as whole country is depends upon seasons, crop types, infestation rates and vegetables for instance, in the rainy season pesticides are usually used each day or in every alternative day. In addition, fast growing vegetables (e. g., brinjal, cabbage, cauliflower, cucumber, lady's finger, yard long bean, tomato etc.) that are to be harvested in alternative days or two-three days in a week receive indiscriminate use of pesticides. The current study found that on an average 4\%, $19 \%, 18 \%$ and $58 \%$ respondents spray pesticides over their vegetable fields in each day, alternative day, two and one times in a week respectively (Table-2).

\subsection{Regulation and collection of vegetables after using pesticide}

According to Dr. Kamal Humayun Kabir, Chief Scientific Officer, PRET, "there are three chemical groups of pesticide used in the country- organophosphate, organocarbamate and synthetic pyrethoite. Among them the level of harm caused by synthetic pyrethoite is low and vegetables should be collected at least four days after its application. Similarly, after using organophosphate and organocarbamet group of chemicals respectively 11 days and 13 days should be left to go before collecting vegetables. Farmers do not always follow the appropriate methods of pesticide use and the waiting period to harvest them which should not be continued".

Surprisingly, very few farmers $(2 \%)$ know that the minimum waiting period of harvesting vegetables after use of pesticides is to be three days following the application of any kind of pesticides while this period can even be extended up to 13 days, based on the chemical nature of pesticides used. Nearly three-fourths (72\%) of the total respondents do not know about the regulation of vegetables collection while $27 \%$ of them do not follow the label of instruction though they are aware that they should do it. In addition, almost half (47\%) of the farmers usually collect vegetables after three days of using pesticides though harvesting time varies with vegetable types; $3 \%, 8 \%, 12 \%$ and $30 \%$ of farmers have been marketing vegetables on the same day, the next day, two days later and three days later, after using pesticides, respectively (Table-2). 
Table-2: pesticide use pattern and pre-cautionary measures taken by users.

\begin{tabular}{|c|c|}
\hline Variables & $\%$ of respondent \\
\hline \multicolumn{2}{|l|}{ Types of pesticide used* } \\
\hline Insecticides & 100 \\
\hline Herbicides & 64.2 \\
\hline Fungicides & 84.2 \\
\hline \multicolumn{2}{|l|}{ Level of pesticide used } \\
\hline According to Packet/bottle label & 23.3 \\
\hline More than instruction & 34.2 \\
\hline Less than instruction & 3.3 \\
\hline According to pesticide dealers' suggestions & 39.2 \\
\hline \multicolumn{2}{|l|}{ Methods of pesticide application } \\
\hline Hand driven sprayer machine & 79.2 \\
\hline Injection & 1.7 \\
\hline Both Hand driven sprayer machine and injection & 19.2 \\
\hline \multicolumn{2}{|l|}{ Interval of pesticides spraying } \\
\hline Every day & 4.2 \\
\hline Alternative day & 19.2 \\
\hline One time in a week & 18.3 \\
\hline Two times in a week & 57.5 \\
\hline \multicolumn{2}{|l|}{ Periods of vegetable collection after using pesticides } \\
\hline That day & 3.0 \\
\hline Next day & 8.0 \\
\hline Two days & 11.7 \\
\hline Three days & 46.7 \\
\hline One week & 30.0 \\
\hline \multicolumn{2}{|l|}{ Pre-harvest period of vegetable after pesticide use } \\
\hline Three days & 1.7 \\
\hline Don't know & 71.7 \\
\hline Don’t follow & 26.7 \\
\hline \multicolumn{2}{|l|}{ Protective measures taken during and after using pesticide } \\
\hline Partial protective clothing & 19.2 \\
\hline Washing hand and face by soap & 1.7 \\
\hline Both measures taken & 72.5 \\
\hline No protective measures taken & 6.7 \\
\hline Smoking, drinking and consuming during pesticides use* & 61.0 \\
\hline Cigarette & 79.0 \\
\hline Water & 15.0 \\
\hline Others(betel leaf, fruits, rice) & 5.0 \\
\hline
\end{tabular}

\subsection{Adoption of protective measures}

(*Multiple-answer considered)

Physical measures: The study found that pesticide users are mostly unaware about protective coverings at the time of handling, transporting, storing and spraying. Although 93\% users take partial safety measures (wearing shirt and loin or trousers) during and after using pesticides, almost all users avoid following proper methods of application. Around $72 \%$ use to wear clothes (shirt or t-shirt) partially as a pre-protective measure before going to spray and cleanse hands and face with soap after finishing. They also take bath after pesticide use for getting rid of odor. On the other hand, 7\% of the users do not take any safety measure, which is a matter of concern regarding farmer's health. It is also shocking to observe that nobody uses mask, eye glass and gumboot, which are to be considered as indispensable safety measures (Table-2).

\subsection{Smoking, drinking and consuming food}

A great many farmers inform smoking cigarettes during pesticide application. About $61 \%$ of respondents reported that they consume something during pesticides application in the fields. Among them the highest proportion of respondents said that they often smoke cigarette $(80 \%)$ and drink water $(15 \%)$ during the period of pesticide application which makes them more vulnerable in terms of users' health (Table-2). 
Plate 1: Pictorial presentation of pesticide usage process in Bangladesh from dealer's godown to spraying and dumping in the agricultural field.
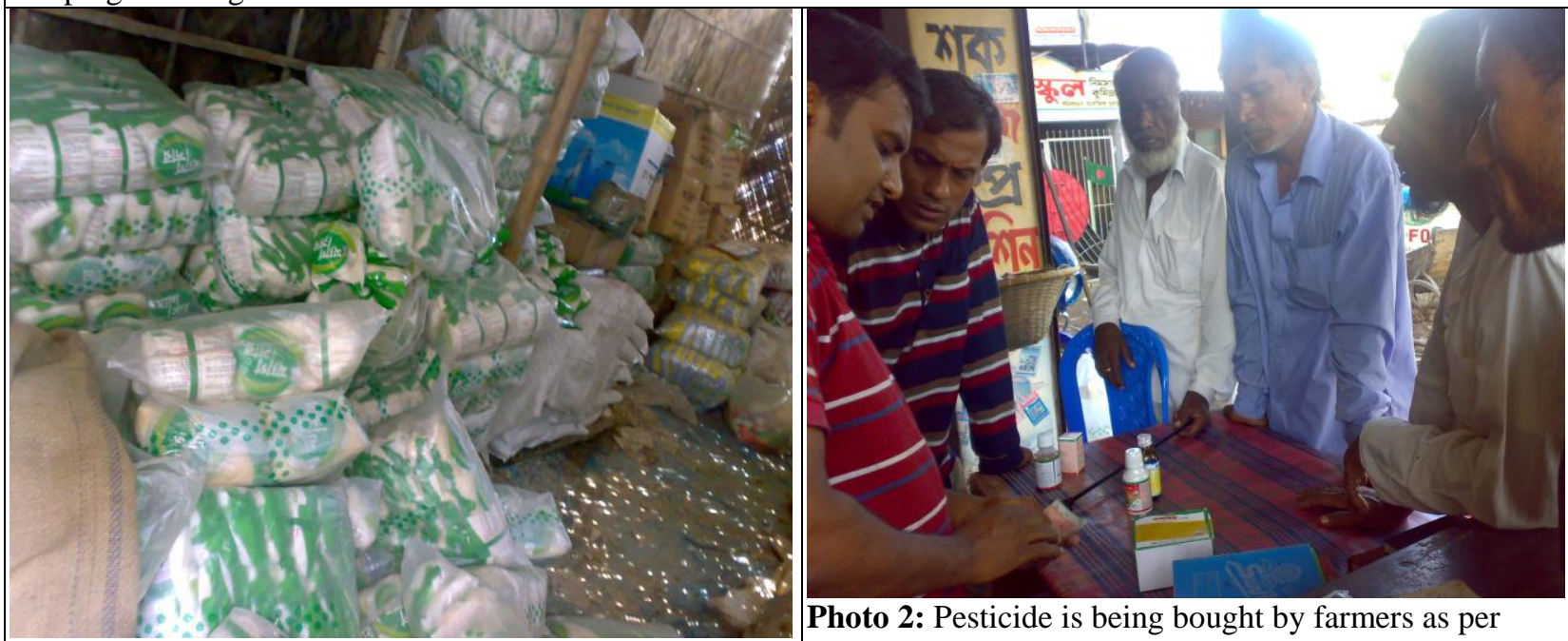

Photo 1: Unsafe storage of pesticide in godown.

Photo 2: Pesticide is being bought by farmers as per

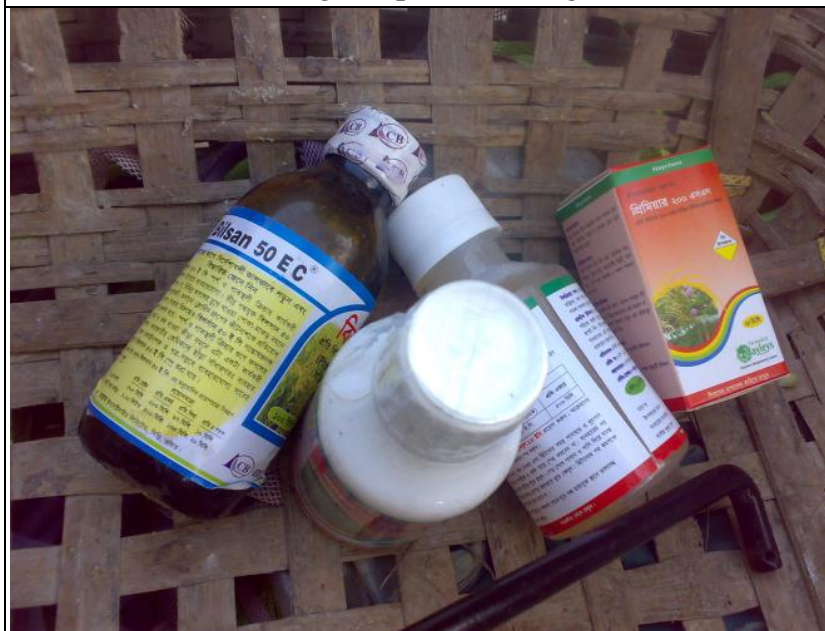
dealer's prescription.

Photo 3: Unsafe way of carrying pesticide.
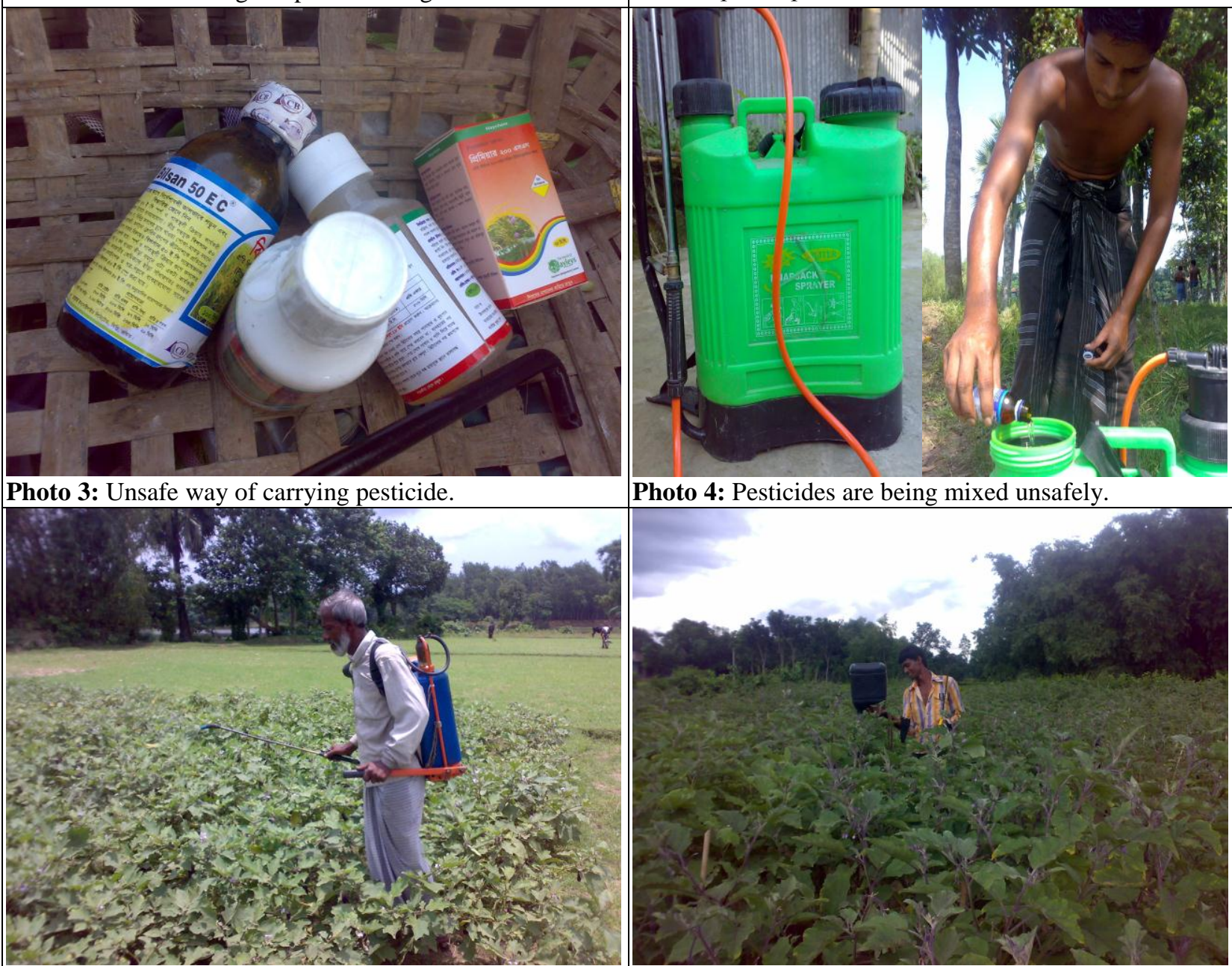

Photo 5: Pesticide spraying without taking proper Photo 4: Pesticides are being mixed unsafely. protection (mask, gloves, eye glasses etc.).

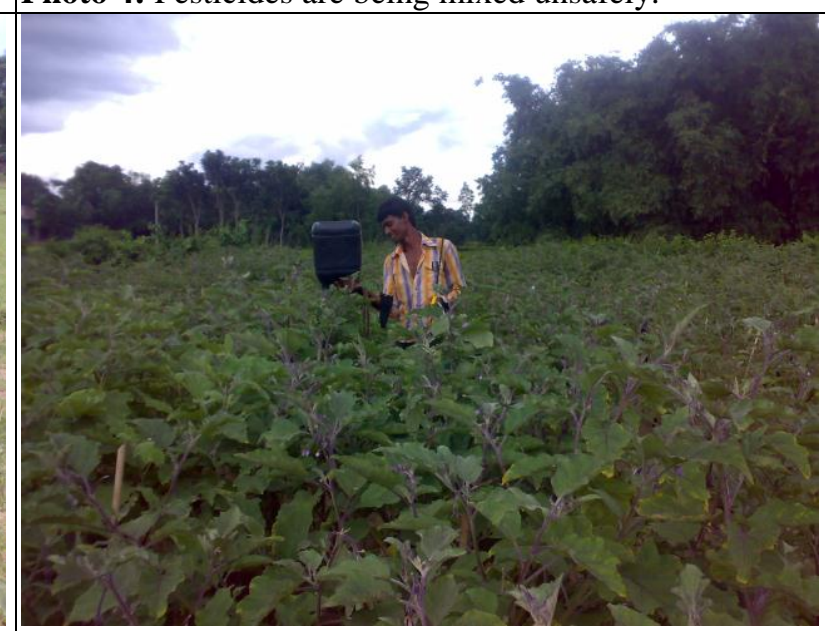

Photo 6: Dumping of remaining pesticide in the container into the field.

\subsection{Impact of pesticides on users' health}

Increasing use of pesticides in the country's agriculture has invoked widespread concern among specialists about their potential ill-effects on human health. Almost all (98\%) respondents think that human health is endangered by pesticide application in the vegetable fields as well as consumption of contaminated 
food. Moreover, farmers particularly who are exposed to pesticides, suffering from at least one health problem such as- skin diseases, eye diseases, gastro-intestinal diseases, urine and sex related diseases, and other short term diseases which has link with pesticide poisoning. Current study found that $55 \%$, 53\%, and $52 \%$ having experience of health hazards i.e., eye irritation, headache and nausea, respectively at the time of pesticide application.

Skin diseases: During the handling, transporting and processing pesticides can come into contact with and enter the body causing various types of skin diseases. Pesticide users in the study area are often exposed dermally; about $61 \%$ reported suffering from skin diseases including irritation and itching (Table-3). According to Burichong Upazila health officers, the number of patients with skin diseases is increasing day by day, mostly among the farming community.

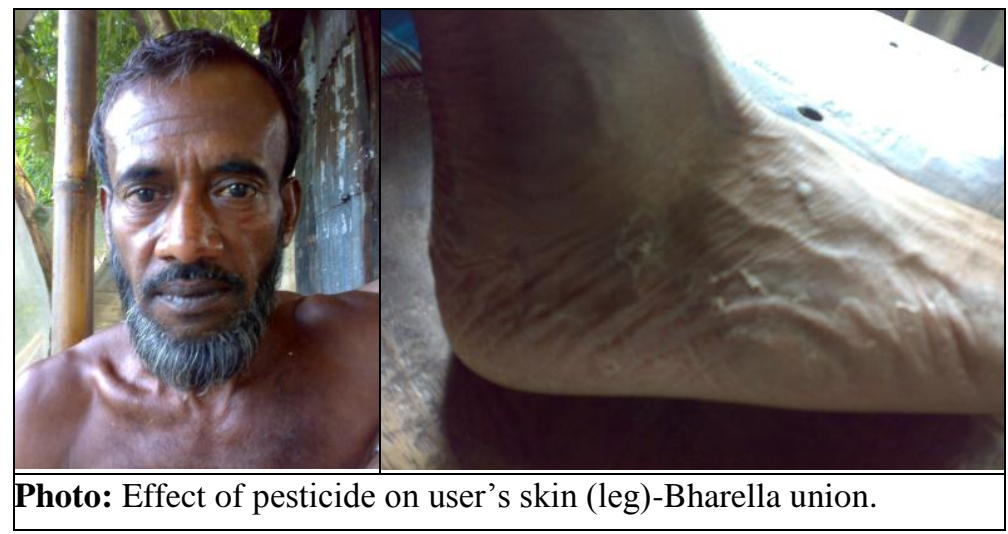

Eye diseases: The present study found that almost all of the farmers spray pesticides without wearing protective eye glasses. About $63 \%$ of total respondents reported having eye problems such as-itching, irritation, pain, cataract, pupil problem and diminished eye sight, either temporarily or permanently. Among them, around $37 \%$ and $7 \%$ are affected by poor vision and eye itching respectively (Table-3). It is shown that the farmers cultivating vegetables as well as using pesticides for a long time (15-19 years) have been suffering from eye diseases more severely. Taufique (age 30), a vegetable grower, said, "one day I sprayed pesticides in the vegetable field against wind direction and some droplet fell on my eyes which resulted in pupil problem(white spot) and suffering till today".

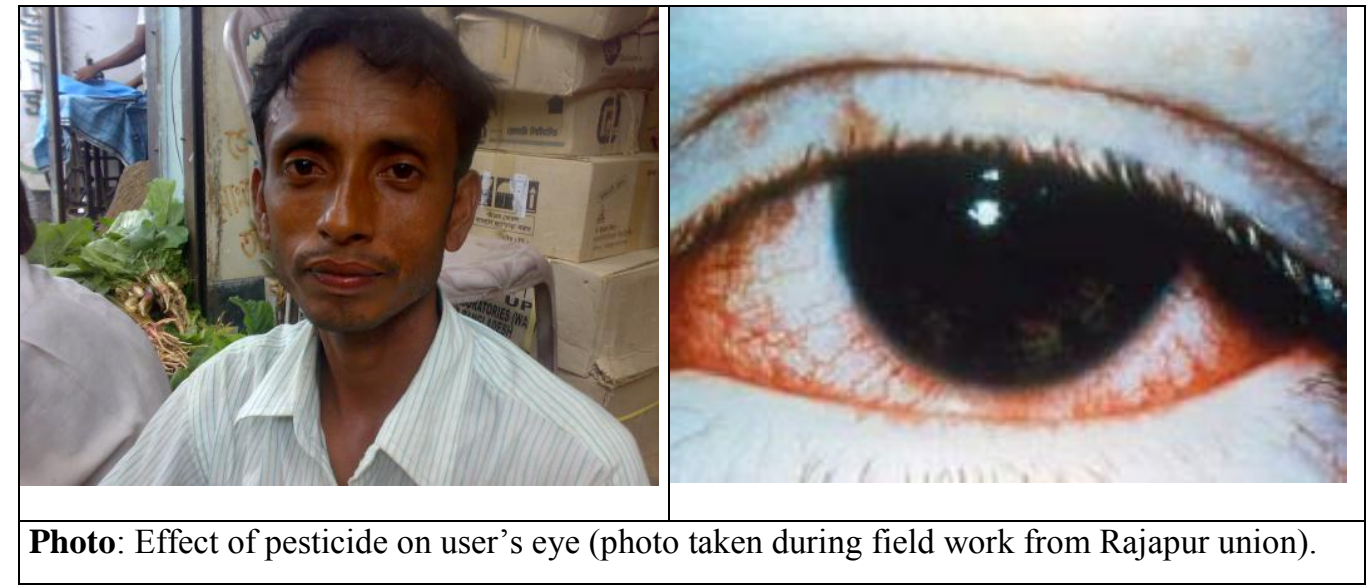

Cancer: According to professor Dr. A.M.M. Shariful Alam, former director of National Cancer and Research Institute and Hospital, Bangladesh, "pesticide is a type of poison and plays a significant role to develop cancer in the human body if it enters into the body through the nose, mouth, ear, eye, skin etc". Although, nobody among the respondents is found to be inflicted with cancer, they reported that people have died before from cancer and that they are seriously concerned about the fact. $98 \%$ of the farmers inform that cancer has been increased in their area and they assume that pesticide has a causal link with it (Table-3).

Gastro-intestinal diseases: Most of the pesticides found in use in the study area are emulsifying concentrate which has a tendency to vaporize and can get mixed with air quickly during spray leading to various types of gastro-intestinal and cardiac problem after inhalation. The survey found that $85 \%$ of applicators are suffering 
from stomachache, digestion problems, loss of appetite and vomiting during and after pesticide application (Table-3). Among these, appetite problem is found at a very high rate (74\%). Some of the respondents complained: "after pesticide spray, I have no willingness to eat something which even lasts up to few days". Shahid (50) a farmer from Bharella union, who has been using pesticide desperately for nearly 30 years explained: "now-a-days I do not feel any appetite for food; even I think I can pass few days without taking any food I strongly believe that this is the result of unsafe and indiscriminate process of applying pesticides". Only $2 \%$ of respondents report that they have experience with vomiting during and after application of pesticides in the vegetables field due to bad odor, but one farmer namely Abdul (40) said "one day while I was spraying in the field, and got seriously ill during pesticide use in my field and some dead worms came out of my belly through the mouth".

Urine and sexual diseases: About 53\% of pesticides users report suffering from various types of urine and sexual diseases such as kidney problems, reduction of urine control and less sexual urge. Although farmers interviewed felt shy to speak about such kind of problems, $32 \%$ confess that they have lost their sexual urge gradually after being introduced to pesticide application in the field (Table-3).

Table-3: Effect of pesticides on users' health.

\begin{tabular}{|c|c|c|c|c|c|c|c|}
\hline \multirow[t]{2}{*}{ Disease pattern } & \multicolumn{7}{|c|}{ \% of respondent (cultivation period in year) } \\
\hline & $<15 \mathrm{yr}$ & $15-19$ yr & $20-24$ yr & $25-29$ yr & $30-34$ yr & $>34$ year & Total \\
\hline Skin diseases & & & & & & & 61.0 \\
\hline Body itching & 9.46 & 8.11 & 6.75 & 1.35 & 8.11 & 0.0 & 33.78 \\
\hline Body irritation & 9.46 & 20.27 & 9.46 & 12.16 & 9.46 & 5.40 & 66.21 \\
\hline Eye diseases & & & & & & & 63.0 \\
\hline Eye pain & 2.63 & 3.95 & 0.0 & 1.32 & 1.32 & 0.0 & 9.2 \\
\hline Eye itching & 1.32 & 3.95 & 1.32 & 0.0 & 0.0 & 0.0 & 6.57 \\
\hline Eye irritation & 1.32 & 5.26 & 3.95 & 1.32 & 2.63 & 2.63 & 17.09 \\
\hline Cataract & 3.95 & 5.26 & 0.0 & 3.95 & 5.26 & 3.95 & 22.37 \\
\hline Little vision & 2.63 & 7.89 & 11.84 & 6.58 & 7.89 & 0.0 & 36.83 \\
\hline Pupil problem & 2.63 & 1.32 & 0.0 & 2.63 & 1.32 & 0.0 & 7.88 \\
\hline Cancer and Ulcer* & & & & & & & \\
\hline Cancer & 20.8 & 25.0 & 17.5 & 10.8 & 19.2 & 5.0 & 98.3 \\
\hline Ulcer & 6.7 & 11.7 & 5.0 & 2.5 & 7.5 & 2.5 & 35.8 \\
\hline Gastro-intestinal diseases* & & & & & & & 85.0 \\
\hline Stomach-ace & 3.92 & 1.96 & 0.0 & 2.94 & 1.96 & 0.98 & 11.76 \\
\hline Digestion problem & 0.98 & 2.94 & 0.98 & 2.94 & 1.96 & 2.94 & 12.74 \\
\hline Loss of appetite & 13.72 & 20.59 & 14.71 & 5.88 & 15.69 & 2.94 & 73.53 \\
\hline Vomiting & 0.0 & 0.0 & 1.96 & 0.0 & 0.0 & 0.0 & 1.96 \\
\hline Urine and sexual diseases & & & & & & & 53.0 \\
\hline Kidney problem & 0.0 & 0.0 & 0.0 & 2.0 & 0.0 & 0.0 & 2.0 \\
\hline Urine control problem & 16.0 & 18.0 & 18.0 & 10.0 & 0.0 & 4.0 & 66.0 \\
\hline Reduction of sexual urge & 4.0 & 14.0 & 6.0 & 2.0 & 4.0 & 2.0 & 32.0 \\
\hline Other diseases* & & & & & & & \\
\hline Physical weakness & 9.2 & 10.8 & 7.5 & 5.8 & 9.2 & 4.2 & 46.7 \\
\hline Vomiting tendency/Nausea & 2.5 & 1.7 & 0.8 & 0.8 & 3.3 & 0.8 & 10.0 \\
\hline Dizziness & 5.8 & 5.8 & 1.7 & 2.5 & 5.0 & 0.8 & 21.7 \\
\hline Chest pain/tightness & 1.7 & 5.8 & 5.0 & 3.3 & 3.3 & 1.7 & 20.8 \\
\hline Muscle twitching & 6.7 & 5.8 & 3.3 & 3.3 & 4.2 & 3.3 & 26.7 \\
\hline Breathing problem & 1.7 & 3.3 & 0.0 & 0.8 & 2.5 & 0.8 & 9.2 \\
\hline Tiredness/Fatigue & 6.7 & 10.8 & 6.7 & 5.0 & 7.5 & 1.7 & 38.3 \\
\hline Excessive sweating & 1.7 & 5.0 & 3.3 & 2.5 & 3.3 & 1.7 & 17.5 \\
\hline Uneasiness/Trouble & 9.2 & 12.5 & 5.8 & 6.7 & 9.2 & 3.3 & 46.7 \\
\hline
\end{tabular}

Others diseases: Our data show that almost all pesticides used by the farmers are of organophosphate chemical group found in different trade names and have been suffering at least one disease while some of them exhibited multi diseases categorized under short term diseases such as- physical weakness, nausea, dizziness, chest pain, muscle twitching, uneasiness and long term diseases such as- breathing problem, excessive sweating and fatigue. Moreover, $47 \%$ report that the physical weakness and uneasiness is experienced during or after their applying pesticides even for a short period of time (Table-3). 


\subsection{Impact of pesticides on vegetable consumers' health}

It is a fundamental right of people is to get safe food for consumption but food materials, particularly agricultural commodities, get contaminated by growers in the name of protection from pests and preservation before they reach consumers. About $85 \%$ of surveyed farmers believe that pesticide-contaminated vegetables will badly affect consumer's health and people may suffer from various types of acute and chronic health problems. Maximum $65 \%$ and minimum $7.5 \%$ of the respondents state that pesticide contaminated vegetables may also be responsible for cancer and muscle contraction respectively (Table-4).

Table -4: Quantification of residue of different insecticides estimated from yard long bean and cucumber samples collected from different local market of Burichong Upazila.

\begin{tabular}{|c|c|c|c|c|c|c|c|}
\hline \multirow[t]{2}{*}{ Vegetable } & \multicolumn{2}{|c|}{ Sample ID } & \multicolumn{5}{|c|}{ Quantity of detected residue (ppm) } \\
\hline & Location & $\begin{array}{l}\text { Sample } \\
\text { code }\end{array}$ & Cypermethrin & Diazinon & Quinalphos & Fenitrothion & Malathion \\
\hline \multirow{3}{*}{$\begin{array}{l}\text { Long } \\
\text { bean }\end{array}$} & Bharella & JLV1 & ND & 0.084 & ND & ND & ND \\
\hline & Mokam & JLM1 & ND & 0.018 & 0.021 & ND & ND \\
\hline & Rajapur & JLR1 & ND & ND & ND & ND & ND \\
\hline \multirow[t]{3}{*}{ Cucumber } & Bharella & JCV1 & ND & ND & ND & ND & ND \\
\hline & Mokam & JCM1 & ND & ND & ND & ND & ND \\
\hline & Rajapur & JCR1 & ND & ND & ND & ND & ND \\
\hline
\end{tabular}

Due to not maintaining the pre-harvesting period appropriately pesticide residues are often found in the marketed vegetables. Moreover, many pesticides are systemic, which means they penetrate into the fruit and vegetable itself and cannot be washed off. There are only six vegetable samples ( 3 long yard bean and 3 cucumber samples) were tested at PRET's Lab in BARI. Two samples of yard long been contained residue of different pesticides i.e. Diazinon ( $0.084 \mathrm{ppm}$ and $0.018 \mathrm{ppm})$ and Quinalphos $(0.021 \mathrm{ppm})$ which was $66.7 \%$ and no residue was detected in cucumber samples (Table-4). Notably, a low quantity of residues is found in the collected samples or in some cases, is not detected even in the vegetables, due to either low spray by the farmers or rain wash. Although the amount of residues are below Maximum Residue Limit (for Quinalphos and Diazinon is $0.2 \mathrm{ppm}$ ), it is above Acceptable Daily Intakes (Quinalphos, $0.002 \mathrm{mg} / \mathrm{kg}$ body weight and Diazinon, $0.004 \mathrm{mg} / \mathrm{kg}$ body weight). It is very distressful that the use of pesticides to control pests on food crops is very dangerous to people who consume those foods even after being washed and cooked.

Table-5: Effect of pesticides on vegetable consumer health.

\begin{tabular}{|c|c|c|c|c|c|c|c|}
\hline \multirow[t]{2}{*}{ Disease pattern } & \multicolumn{7}{|c|}{$\%$ of respondent (cultivation period in year) } \\
\hline & $<15 \mathrm{yr}$ & $15-19 \mathrm{yr}$ & $20-24$ yr & $25-29$ yr & $30-34$ yr & $>34$ year & Total \\
\hline Skin disease & 5.0 & 5.0 & 1.7 & 0.0 & 1.7 & 1.7 & 15.0 \\
\hline Eye problem & 3.3 & 8.3 & 7.5 & 3.3 & 4.2 & 1.7 & 28.3 \\
\hline Headache & 2.5 & 4.2 & 2.5 & 1.7 & 1.7 & 0.8 & 16.0 \\
\hline Cancer & 12.5 & 15.8 & 11.7 & 10.0 & 10.8 & 4.2 & 65.0 \\
\hline Ulcer & 8.3 & 9.2 & 11.7 & 6.7 & 10.0 & 4.2 & 50.0 \\
\hline Stomachache & 15.0 & 8.3 & 12.5 & 5.8 & 9.2 & 3.3 & 54.2 \\
\hline Digestion problem & 11.7 & 10.0 & 11.7 & 5.8 & 9.2 & 2.5 & 50.8 \\
\hline Loss of appetite & 12.5 & 10.8 & 10.0 & 5.8 & 9.2 & 3.3 & 51.7 \\
\hline Vomiting & 11.7 & 10.0 & 5.8 & 3.3 & 5.8 & 0.8 & 37.5 \\
\hline Kidney problem & 7.5 & 6.7 & 2.5 & 0.8 & 2.5 & 1.7 & 21.7 \\
\hline Reduction of sexual urge & 4.2 & 1.7 & 1.7 & 2.5 & 1.7 & 0.0 & 11.7 \\
\hline Urine control problem & 5.8 & 3.3 & 1.7 & 1.7 & 0.8 & 0.8 & 14.2 \\
\hline Body irritation & 5.0 & 3.3 & 3.3 & 0.8 & 5.8 & 2.5 & 20.8 \\
\hline Physical weakness & 8.3 & 11.7 & 9.2 & 5.0 & 5.8 & 2.5 & 42.5 \\
\hline Dizziness & 3.3 & 3.3 & 1.7 & 1.7 & 1.7 & 1.7 & 13.3 \\
\hline Chest pain/tightness & 1.7 & 4.2 & 0.8 & 1.7 & 1.7 & 0.0 & 12.0 \\
\hline Muscle twitching & 2.5 & 0.0 & 1.7 & 1.7 & 0.8 & 0.8 & 7.5 \\
\hline Breathing problem & 4.2 & 5.8 & 2.5 & 2.5 & 1.7 & 2.5 & 19.2 \\
\hline Uneasiness/Trouble & 15.0 & 13.3 & 10.0 & 8.3 & 10.0 & 3.3 & 60.0 \\
\hline
\end{tabular}

More than half of the respondents report that cancer (65\%), uneasiness $(60 \%)$, stomach-ache (54\%), appetite loss $(52 \%)$, digestion problem (51\%) and ulcer (50\%) might have resulted from consuming pesticide contaminated-vegetables (Table-5). 


\section{Conclusion}

Farmers of Bangladesh are mostly use insecticides of organophosphate chemical group rather than other types of pesticides. Generally, they are not much aware of pesticide toxicity and protective measures which must be taken at the time of and after handling, carrying, mixing, storing or any other type of contact with and disposal of pesticides. Moreover, pesticides user are smoking, drinking and consuming something during application resulting suffering from pesticide related both acute and chronic health hazards. It is mentionable that among the pesticides users who have been cultivating vegetables for 15-19 years are suffering much, since the widespread use of pesticides in Bangladesh are started after 1990.

It is assumed that it's really difficult to find pesticide residue free vegetables, foods and fruits in our country at present. Study also reveals that about three-fourths of the marketed vegetable (long yard been) contain pesticide residue. As a consequence of consuming chemical impregnated vegetables, people sometimes need to take treatment and spend a lot of money in it, which is related to their personal, as well as country's national economy. The present study suggests that the government and other concerned authorities need put into effect pragmatic initiatives across the country in favour of implementing all policies and regulations related to pesticide application which ensure steady crops and vegetables production as well as sound public health. In addition, arrangement of free access to training programs for farmers about judicious and safe use of pesticides would raise awareness among the farmers. Consumers about the toxicity of pesticides through mass media- both print and electronic, along with the use of other digital advantages such as sending emails and mobile messages to them for getting rid of this silent disaster. The risk could be reduced if vegetables are washed and cooked well to remove residues before consumption as well as avoid pesticide ridden foods. To know the precise impact of pesticide on users and consumers health need biomedical long term study in nationwide.

\section{References}

[1] Bangladesh Economic Review, Ministry of Finance and Planning, Government of the Peoples Republic of Bangladesh, Dhaka, 2010 .

[2] Kabir KH, Rahman MA, Ahmed MS, Prodhan MDH and Akon MW, Pesticide analytical research at BARI related to quality, residue and maximum residue limit, in Chowdhury, MKA et al. (Eds), Proceedings of Workshop on Maximum Residue Limits of Pesticides in Agricultural Commodities and Food in Bangladesh, (Bangladesh Agricultural Research Council, Dhaka, 2008).

[3] BBS, Statistical Yearbook of Bangladesh, Bangladesh Bureau of Statistics, Planning division, Ministry of Planning, Government of the Peoples Republic of Bangladesh, Dhaka, 2008 and 2009.

[4] Gain P, Pesticide Doesn't Guarantee Increased Crop Yield, in Gain, P. et al. (Eds), Bangladesh Environment: Facing the 21 ${ }^{\text {st }}$ Century, (Society for Environment and Human Development (SEHD), Dhaka, 1998).

[5] Sattar, M. A. Ahmed, Use of pesticides in Bangladesh and protection of the environment, proceeding of the seminar on protecting the environment from degradation, SAARC, Dhaka, 1985, pp 58-63.

[6] Ali SMK, Rahman MM, Hossain AMMM, Pesticide use and male fertility in Bangladesh, in Ahmed M F. et.al, (Eds), Bangladesh Environment 2002, (Bangladesh Paribesh Andolon (BAPA), 2002), Vol-1.

[7] NOVIB, Pesticides Misuse in Bangladesh, The Pesticides Trust, London: U.K., Dec. 1993.

[8] Meisner C, Report of pesticide hotspots in Bangladesh, Report to the Canadian International Development Agency, Mimeo, World Bank: Washington DC, 2004. Available at: http://www.worldbank/nipr.

[9] SUNS, Pesticide overuse takes serious turn in Bangladesh, Jan. 23, 1998.

[10] SOS-Arsenic.net, Agrochemicals: Imported Pollutants in Bangladesh, 2004. Available at: http://www.sos-arsenic.net/index.html.

[11] Anonymous, Annual report 1999-2000, Entomology division, Bangladesh Agricultural Research Institute, Dhaka, 2000.

[12] The Daily Prothomalo, Dhaka, July $20 \& 21,2008$

[13] Daily Star, Pesticides may also kill ignorant farmers, Jan 5, 2010. Available at: http://www.bd64.com/today1.php?id=9525.

[14] Dasgupta S, Meisner C and Huq M, Health effects and pesticide perception as determinants of pesticide use: Evidence from Bangladesh, World Bank Policy Research Working Paper no. WPS 3776, November 2005.

[15] Ogg CL and Schulze LD, Managing the risk of pesticide poisoning and understanding the signs and symptoms, University of Nebraska-Lincoln Extension, Extension Circular EC2505, 2006. Available at: http://ianrpubs.unl.edu/epublic/live/ec2505/build/ec2505.pdf

[16] Jaga K, Dharmani C, Sources of exposure to and public health implications of organophosphate pesticides, Rev. Panam, Salud Publication, 2003, 14 (3): 171-85, doi:10.1590/S1020-49892003000800004, PMID 14653904.

[17] Ecobichon DJ, Toxic effects of pesticides, in Casarett and Doull's, Toxicology: The Basic Science of Poisons, (New York: MacMillan, 1996), 5th ed.: 643-689.

[18] Zahm SH, Ward MH and Blair A, Pesticides and Cancer, in Keifer M. (Eds.), Occupational Medicine: State of the Art Reviews, (Philadelphia: Hanley and Belfus, Inc., 1997) Vol. 12: 269-289.

[19] Bassil KL, Vakil C, Sanborn M, Cole DC, Kaur JS and Kerr KJ, Cancer health effects of pesticides: systematic review, Can Fam Physician 53 (10): 1704-11, October 2007. PMID 17934034.

[20] Schreinemachers DM, Creason JP \& Garry VF, Cancer mortality in agricultural regions of Minnesota, Environmental Health Perspectives 107:205-11, 1999.

[21] Alavanja MC, Hoppin JA, Kamel F., Health effects of chronic pesticide exposure: cancer and neurotoxicity, Annu Rev Public Health 25:15597, 2004, doi:10.1146/annurev.publhealth.25.101802.123020. PMID 15015917.

[22] Kamel F, Hoppin JA., Association of pesticide exposure with neurologic dysfunction and disease, Environ. Health Perspect. 112 (9): 950-8, June 2004. PMID 15198914.PMC 1247187.

[23] Colborn T, Myers JP and Dumanoski D., Our stolen future: how we are threatening our fertility, intelligence, and survival: a scientific detective story, New York: Dutton, 1996. 
[24] EPA US, Pesticides: Health and Safety, National Assessment of the Worker Protection Workshop \#3, August 30, 2007. available at: http://www.epa.gov/pesticides/health/human.htm

[25] Moses M, Pesticides killers in our midst, in Nair K P. (Eds) Warning: Pesticides are Dangerous to Your Health, (Penang: Pesticide Action Network Asia and the Pacific, 1999).

[26] Sanborn M et al., Systematic Review of Pesticide Human Health Effects, Toronto: Ontario College of Family Physicians Toronto, 2004. Available from: http://www.ocfp.on.ca/local/files/Communications/Current\%20Issues/Pesticides/Final\%0Paper\% 2023APR2004.pdf.

[27] Kishi M, Hirschhorn N, Qjajadisastra M, Satterlee L N, Strowman S and Dilts R, Relationship of pesticide spraying to signs and symptoms in Indonesian farmers, Scandinavian Journal of Work \& Environmental Health 21: 124-133, 1995.

[28] Pimental D, Acquay H and Biltonen M, Environmental and economic costs of pesticide use, Bioscience 42:750-60, 1992.

[29] Rosenstock L, Keifer M, Daniell WE, McConnell R, Claypoole K, Chronic central nervous system effects of acute organophosphate pesticide intoxication, Lancet 338: 223-227, 1991.

[30] Sarker MMR, Alam MS and Akthar N, Pesticide use in Modern Rice Production: The Issue of Farmers Health and Environment, in Ahmed MF et al. (Eds), Bangladesh Environment 2002, (Bangladesh Paribesh Andolon (BAPA), Dhaka, 2002), Vol-1.

[31] WHO, Public health impact of pesticides used in agriculture, World Health Organization: New York, USA, 1990.

[32] Rahman A et al. (eds.), Poison in the field, in Peoples Report on: Bangladesh Environment 2001, (The university press limited, Dhaka, 2001), Vol-I.

[33] Taher M., Export earning at stake: Pesticide residue in vegetable and fish, in Faruk M. et al. (Eds), Poribesh o Anushandani Sangbadikata, (Bangladesh Environmental Law Association (BELA), Dhaka, 1996).

[34] Rahman MA, Prodhan MDH, Akon MW, Ahmed MS and Kabir K H., Multi insecticide residue analysis in environmental sample collected from different regions of Bangladesh, Annual Report 2009-2010, Entomology division, Bangladesh Agricultural Research Institute, Dhaka, 2010, pp.151-158.

[35] Opinion Research Corporation, Trends, consumer attitudes, and the supermarket, Food Marketing Institute, Washington, DC, 1990.

[36] Daily Star, Poison Found in Dhamrai, Dhaka, June 1, 2009. 